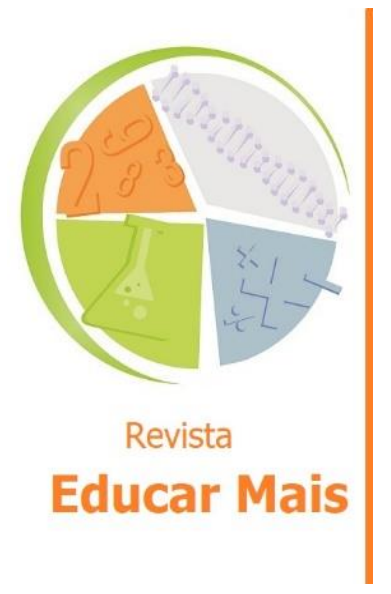

\section{Da ação à emancipação: o uso do ambiente virtual de aprendizagem do GeoGebra no contexto da educação popular}

\begin{abstract}
From action to emancipation: the use of the virtual environment for learning GeoGebra in the context of popular education
\end{abstract}
De la acción a la emancipación: el uso del entorno virtual para el aprendizaje de GeoGebra en el contexto de la educación popular

Rodrigo Sychocki da Silva1; Thor Franzen²

\title{
RESUMO
}

O presente artigo versa sobre uma pesquisa de característica qualitativa realizada no ano de 2019 com uma turma do pré-vestibular popular Dandara dos Palmares, sediado no Instituto Federal do Rio Grande do Sul (IFRS) em Porto Alegre. A produção dos dados ocorreu na forma da aplicação de uma proposta didática presencial no laboratório de informática da instituição, aonde os participantes exploraram atividades sobre funções afins e funções quadráticas fazendo uso de um Ambiente Virtual de Aprendizagem e também fizeram o preenchimento de dois questionários. Utilizamos como fundamentação teórica estudos e autores que apresentam as ideias da Educação Popular e sobre o uso das tecnologias digitais em sala de aula na perspectiva da formação de professores. A análise mostrada no presente artigo centra-se nos dados apresentados nos questionários, os quais demonstram por parte dos participantes da pesquisa uma valorização do uso das tecnologias no percurso de aprendizagem. Entende-se assim, que ao fazer uso das tecnologias em atividades didático-pedagógicas na Educação Popular os estudantes tornam-se os principais agentes no processo de aprendizagem.

Palavras-chave: Aprendizagem; Ambiente Virtual de Aprendizagem; Educação Popular; Tecnologias Digitais.

\begin{abstract}
This article deals with a qualitative research carried out in 2019 with a group of the popular pre-university entrance exam Dandara dos Palmares, based at the Federal Institute of Rio Grande do Sul (IFRS) in Porto Alegre. The production of the data occurred in the form of the application of a didactic proposal in person at the institution's computer lab, where the participants explored activities on related functions and quadratic functions using a Virtual Learning Environment and also completed two questionnaires. We use as a theoretical foundation studies and authors that present the ideas of Popular Education and on the use of digital technologies in the classroom from the perspective of teacher training. The analysis shown in this article focuses on the data presented in the questionnaires, which demonstrate by the research participants an appreciation of the use of technologies in the learning path. It is understood, therefore, that when using technologies in didacticpedagogical activities in Popular Education, students become the main agents in the learning process.
\end{abstract}

Keywords: Learning; Virtual learning environment; Popular Education; Digital Technologies.

\footnotetext{
${ }^{1}$ Doutor em Informática na Educação e professor Adjunto do Departamento de Matemática Pura e Aplicada (DMPA) do Instituto de Matemática Pura e Aplicada da Universidade Federal do Rio Grande do Sul (UFRGS). E-mail: sychocki.rodrigo@gmail.com

2 Licenciado em Matemática pela UFRGS e mestrando no programa de Pós-Graduação em Ensino de Matemática na Universidade Federal do Rio Grande do Sul (UFRGS). E-mail: thor.franzen1903@gmail.com
} 


\section{RESUMEN}

Este artículo trata de una investigación cualitativa realizada en 2019 con un grupo de la popular prueba de acceso preuniversitaria Dandara dos Palmares, con sede en el Instituto Federal de Rio Grande do Sul (IFRS) en Porto Alegre. La producción de los datos se dio en forma de la aplicación de una propuesta didáctica presencial en el laboratorio de computación de la institución, donde los participantes exploraron actividades sobre funciones relacionadas y funciones cuadráticas utilizando un Ambiente Virtual de Aprendizaje y además completaron dos cuestionarios. Utilizamos como fundamento teórico estudios y autores que presentan las ideas de la Educación Popular y sobre el uso de las tecnologías digitales en el aula desde la perspectiva de la formación docente. El análisis que se muestra en este artículo se centra en los datos presentados en los cuestionarios, que demuestran por parte de los participantes de la investigación una apreciación del uso de tecnologías en la ruta de aprendizaje. Se entiende, por tanto, que al utilizar tecnologías en actividades didáctico-pedagógicas en Educación Popular, los estudiantes se convierten en los principales agentes en el proceso de aprendizaje.

Palabras clave: Aprendizaje; Ambiente de aprendizaje virtual; Educación Popular; Tecnologías digitales.

\section{INTRODUÇÃO}

O ano de 2020 causou um impacto na educação. Por conta de uma pandemia de proporções globais, muitas escolas foram fechadas, uma vez que dependem da reunião presencial de inúmeras pessoas em uma mesma sala de aula. Com isso, os professores se viram "presos" em casa e criou-se a necessidade de ministrar aulas a distância, o que trouxe dificuldades, que, aos poucos, parecem ser melhor compreendidas pelos envolvidos no contexto educacional de certa forma.

Uma primeira dificuldade que se fez presente é referente ao acesso à internet. A pandemia evidenciou uma desigualdade no nosso país, causando um impacto na educação, sendo este mais sentido pela população mais pobre. Apesar de $70 \%$ dos lares urbanos brasileiros estarem conectados à internet, os números tomam outras proporções quando estratificados. Entre as classes $A$ e $B$ (com renda familiar acima de 8,6 mil reais) 96,5\% das casas têm sinal de internet fixa, enquanto esse indicador diminui para $41 \%$ quando olhamos para as classes $D$ e $E$, que possuem renda familiar máxima de 1254 reais. Outro fator a ser observado é de que maneira esse acesso é feito, visto que para as classes na base da pirâmide social, $78 \%$ das pessoas que conseguem navegar na rede utilizam exclusivamente o telefone celular ${ }^{3}$. Esse quadro mostra a dificuldade daqueles que lutam por uma educação universal e de qualidade estão a enfrentar.

A prática de pesquisa a qual faz referência esse artigo foi realizada com uma turma do Pré-Vestibular Popular (PVP) Dandara dos Palmares em Porto Alegre (RS), território da Educação Popular, construído pelo trabalho de diversos voluntários desde 2016 e sediado no Instituto Federal de Educação, Ciência e Tecnologia do Rio Grande do Sul (IFRS). Com o cenário apresentado no parágrafo anterior, era de se esperar que a Educação Popular, com suas sedes físicas fechadas, fosse impactada à medida que se avizinhava o contexto da educação a distância para a continuidade do presente ano letivo. No primeiro semestre de 2020, as ações do PVP Dandara dos Palmares acabaram limitadas a disposição de material didático por meio de redes sociais (que, em geral, possuem maior oferta de acesso pelas operadoras de telefonia). Entretanto no início do segundo semestre, com uma doação de uma organização não-governamental dedicada a distribuir acesso universal à internet, conseguimos

\footnotetext{
${ }^{3}$ Fonte: https://g1.globo.com/educacao/noticia/2020/05/05/sem-internet-merenda-e-lugar-para-estudar-vejaobstaculos-do-ensino-a-distancia-na-rede-publica-durante-a-pandemia-de-covid-19.ghtml. Acesso em dezembro de 2020.
} 
distribuir planos de internet para os alunos, junto com materiais didáticos físicos e cartilhas guia de estudos. As aulas a distância estão programadas para começar no segundo semestre de 2020.

O contexto que será exposto e analisado aqui ocorreu em 2019 com as turmas do PVP Dandara dos Palmares no laboratório de informática utilizando o Ambiente Virtual de Aprendizagem (AVA) do GeoGebra. Mesmo tendo sido realizada de forma presencial entendemos que o conjunto de atividades tem potencial para ser adaptado para a realização à distância, contribuindo assim para ações docentes que envolvem o contexto do ensino remoto. Na próxima etapa do artigo apresenta-se o referencial teórico da pesquisa, com reflexões que consideramos pertinentes e que abrangem ideias sobre Educação Popular e tecnologias. A terceira seção é sobre a metodologia, seguida de uma análise dos questionários utilizados com os estudantes. Ao final explanam-se as considerações finais, com nossas reflexões a partir da pesquisa realizada e tecendo possíveis conjecturas para a continuidade do trabalho.

\section{APORTES TEÓRICOS: UM CONJUNTO DE REFLEXÕES DAS IDEIAS DE FREIRE ÀS TECNOLOGIAS}

A Educação Popular (EP) é uma prática educativa cujo ponto de partida é a realidade social. Ela é um movimento civil de educadores identificados com a educação libertadora e possui uma base simbólicoideológica de processos políticos de organização e mobilização de setores das classes populares. $\mathrm{Na}$ literatura é possível identificar que a EP é alicerçada na soberania do povo, na justiça social e no respeito integral aos direitos humanos (BRANDÃO, 2006; PINI e ADRIANO, 2011; PEREIRA e PEREIRA, 2010).

O uso das TIC no contexto educacional, primeiramente com um olhar específico para a EP, se faz necessário tendo como foco a inclusão digital. Os smartphones e computadores estão difundidos entre a sociedade, todavia a exclusão digital precisa ser combatida, ainda mais levando em conta que ela não é exatamente um distanciamento da tecnologia, mas sim a incapacidade de utilizá-las de maneira crítica, se faz necessário um olhar para a inclusão digital de uma forma dialética, "deixando de lado qualquer iluminismo ingênuo ou perspectivas assistencialistas e de distribuição de equipamentos" (FANTIN; GIRARDELLO, 2009, p.72).

A inserção das tecnologias no cotidiano exige uma capacitação cada vez maior das pessoas para seu uso (MADRUGA, 2017). Segundo Fantin e Girardello (2009), a educação renuncia à socialização dos conhecimentos aliados aos valores humanos quando enfatiza o tecnicismo instrucional. Temos então o argumento da cidadania, que afirma: "programas sociais de inclusão digital são praticados como possibilidade de acesso a tecnologias da informação e comunicação, as quais são importantes para que se promovam os direitos políticos, civis e sociais" (MASSENSINI, 2011, p. 1). Com isso, a inclusão digital tem papel crucial no exercício da cidadania plena, pois garante o acesso à informação (inclusive ao conhecimento dos direitos humanos), bem como o direito à livre manifestação e participação política, revelando um papel importante da inclusão digital no contexto da EP.

Segundo Alencar (2009), Paulo Freire faz referência às tecnologias em praticamente todas as suas obras, apesar de não ser o tema central de seu trabalho, oferecendo um olhar otimista, curioso e crítico. Ele entendia a tecnologia como partícipe no desenvolvimento humano, sendo "a expressão natural do processo criado em que os seres humanos se engajam no momento em que forjam o seu primeiro instrumento com que melhor transformam o mundo" (FREIRE, 1975, p. 98 apud ALENCAR, 
2009, p. 164). Paulo Freire reconheceu as potencialidades no uso das TIC no seu livro intitulado "Pedagogia da Esperança", em que ele afirma: "Ao recordar agora todo este trabalho tão artesanal, até com saudade, reconheço o que teria poupado de tempo e de energia e crescido em eficácia se tivesse contado, na oportunidade, com um computador, mesmo humilde (...)" (FREIRE, 1992, p.59).

Paulo Freire defendia que os computadores eram extraordinários, e nessa linha visualizamos que ele ficaria ainda mais maravilhado com os smartphones. Porém, seu uso não deveria ser numa perspectiva de alienação, em que fosse ensinada apenas alguma técnica sem uma reflexão e discussão ao fazer uso da tecnologia, reflexão essa que é entendida aqui como o alicerce da EP (ALENCAR, 2009; FREIRE, 2013; FREIRE, 2001).

A educação não se reduz à técnica, mas não se faz educação sem ela. Utilizar computadores na educação, em lugar de reduzir, pode expandir a capacidade crítica e criativa de nossos meninos e meninas. Dependendo de quem o usa, a favor de que e de quem e para quê. $O$ homem concreto deve se instrumentar com o recurso da ciência e da tecnologia para melhor lutar pela causa de sua humanização e de sua libertação. (FREIRE, 2001, p. 98)

Observando o trabalho de outros autores que estudaram a visão freireana das tecnologias aplicadas à educação, destacamos o trabalho de Soffner (2013) que reforça a importância da inclusão digital, ao afirmar que "a construção de uma nova educação deverá tirar proveito, mas também garantir o acesso à informação e aos conteúdos, fazendo do educando um descobridor" (SOFFNER, 2013, p. 159). Conte, Habowski e Rios (2018) destacam a importância da educação emancipatória e a formação cidadã com o uso de tecnologias, o que depende da formação de professores qualificados para a utilização das tecnologias.

Para tanto, destaca-se a percepção da necessidade de formação dos docentes para o uso criativo e reconstrutivo das tecnologias, considerando não só as capacidades técnicas, mas, principalmente, despertando as capacidades cognitivas, expressivas e crítico-reflexivas para pensar o desenvolvimento desses recursos. (CONTE; HABOWSKI; RIOS, 2018, p. 9)

Ao se trabalhar com núcleos para cada disciplina, e ser especialmente atrativo para graduandos dispostos ao trabalho voluntário, a EP é um terreno fértil para a formação de professores. É necessário mencionar que algumas instituições que ofertam essa modalidade de ensino ainda tenham dificuldades estruturais de oferecer uma formação tecnológica tanto para alunos quanto para professores. O curso Dandara dos Palmares - e os outros dois cursos sediados no IFRS, Território Popular e TransENEM - podem usufruir dos laboratórios de informática da instituição, provendo uma democratização das mídias digitais, e possibilitando o trabalho dos professores na direção de uma formação tecnológica que seja, ao nosso entendimento, imprescindível para uma educação que visa a emancipação dos educandos, especialmente nos dias de hoje.

No sentido de uma educação em prol da emancipação e que seja amplamente difundida aos que dela participam, entendemos que os estudos que fazem uso do software GeoGebra tenham um diferencial. O GeoGebra tem uma aplicação que pode ser instalada em qualquer computador com sistema operacional compatível, ele também conta com um endereço eletrônico (geogebra.org) em que estão disponíveis para uso no navegador as ferramentas oferecidas pelo aplicativo. O site foi escolhido para o trabalho da pesquisa não só por não requerer uma instalação prévia do software, mas também por oferecer o GeoGebraGroups como funcionalidade, fazendo o papel de Ambiente Virtual de Aprendizagem (AVA). Os AVAs são softwares educacionais via internet, destinados a apoiar as atividades de educação a distância, semipresencial ou presencial. Eles oferecem um conjunto de 
tecnologias de informação e comunicação, que permitem desenvolver as atividades no tempo, espaço e ritmo de cada participante (RIBEIRO et al., 2007). Eles (AVAs) contribuem para o melhor aproveitamento da educação e aprendizagem em contextos não presenciais, pois oferecem diversos recursos para a realização das aulas e interações entre professores e alunos (RIBEIRO et al., 2007, p. 4).

Nesse sentido, entendemos que o uso de um AVA, especificamente do GeoGebraGroups, como ferramenta de ensino possa chamar a atenção por permitir um acesso dos alunos à sequência didática proposta pelo professor tanto em sala de aula quanto em casa, ou seja, demonstra o surgimento de vantagens para o trabalho do docente e incentiva o estudo do discente independente do lugar onde ele esteja. Segundo Dotta (2011) os ambientes virtuais de aprendizagem são centrados em conteúdos e atividades de aprendizagem pré-determinada, cujo processo já está previsto de antemão. Ainda de acordo com o autor, esses devem oportunizar ajuda tutorial rapidamente acessível, vários meios de informação integrados, conteúdos enfocados a partir de diferentes pontos de vista, possibilidade de interagir com diferentes conteúdos, contato com o professor e o planejamento detalhado da estrutura de aprendizagem. As atividades construídas, e que constituíram o conjunto de dados a serem explorados no campo de nossa pesquisa, constitui um AVA organizado por meio de um espaço virtual disponibilizado no GeoGebraGroups.

A próxima seção faz um delineamento sobre a metodologia da realização da tarefa no laboratório de informática, bem como as características para a análise do AVA do GeoGebra, que consta na quarta seção.

\section{METODOLOGIA}

A composição da atividade, a análise dos dados e a atuação do professor no lugar de pesquisa foram realizadas apoiadas na abordagem qualitativa, de caráter fenomenológico, que, segundo Bicudo (2013), torna a investigação uma pesquisa da realidade dos sujeitos, que são convidados a pensar no que faz sentido para eles. Segundo a autora, a fenomenologia "coloca em evidência a linguagem, entendida como expressão do sentir, e o discurso, entendido como articulação daquilo que faz sentido. Trabalha desse modo, o sentido e o significado" (BICUDO, 2013, p. 120).

$\mathrm{Na}$ prática de pesquisa, os estudantes do pré-vestibular popular Dandara dos Palmares tiveram contato com duas atividades, uma sobre função afim e outra sobre função quadrática, disponibilizadas no AVA GeoGebraGroups. As atividades foram realizadas nos laboratórios de informática do IFRS de maneira presencial com dois períodos destinados para a realização de cada uma. A turma participante da pesquisa era composta por 28 estudantes, sendo que 25 autorizaram o uso das informações para a pesquisa. As atividades encontram-se atualmente disponíveis na internet, e podem ser acessadas por meio dos códigos Quick Response (QR) mostrados na Figura 1.

Figura 1: Códigos QR para acesso as atividades.

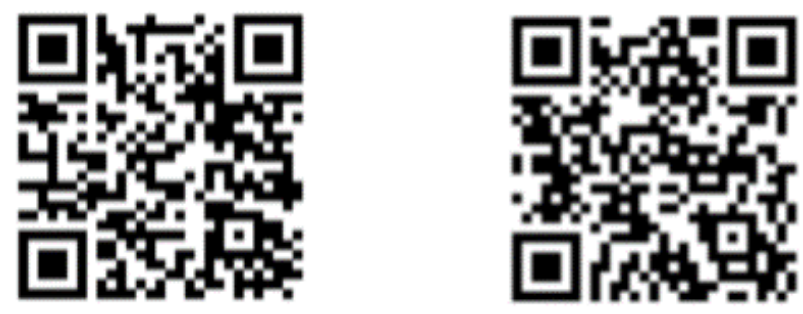

Fonte: Os autores. 
Os dados foram produzidos a partir das respostas dos estudantes frente às duas atividades, uma sobre função afim e outra sobre função quadrática, e também a partir das respostas fornecidas a dois questionários, um ocorrido antes das atividades e outro ao final.

\section{UMA ANÁLISE DAS NARRATIVAS DOS ESTUDANTES EXPOSTAS NOS QUESTIONÁRIOS}

O primeiro questionário recebeu 21 respostas, que revelam dados sobre o perfil dos alunos e como eles acessam a internet. Na primeira pergunta sobre os aparelhos utilizados com acesso à rede mundial de computadores, 19 alunos marcaram que utilizam smartphones, sendo essas mais de $90 \%$ das respostas recebidas. Doze afirmaram possuírem computadores próprios, enquanto 6 utilizam o computador de terceiros. Apenas um aluno afirmou possuir um tablet em casa.

A seguir, foi perguntado aos participantes da pesquisa como eles avaliam de 1 a 5 o conhecimento deles sobre o software GeoGebra. Dez alunos marcaram 1 para "nunca tive contato", e outros onze, configurando maioria, marcaram algo maior ou igual a dois, sendo três respostas número 5 - "sou craque". Isso mostra algum impacto no ambiente do trabalho do professor, tendo em vista que 5 alunos estavam no momento da pesquisa há dois anos na turma e já tiveram contato com o aplicativo pois participaram de uma atividade similar em outro momento.

A última pergunta do primeiro questionário era dissertativa e solicitava que os alunos apontassem as suas opiniões sobre o uso de mídias digitais em sala de aula e se há potencialidades na melhoria do ensino. Destacam-se potencialidades apontadas pelos estudantes como a relação entre a juventude e a internet, facilitando o aprendizado e os estudos, ou como o aluno que configurou a atividade como inútil, mas observando o plano piloto de aplicação digital do ENEM, conforme podem ser observadas na imagem a seguir.

Figura 2: Captura de tela dos envios dos estudantes.

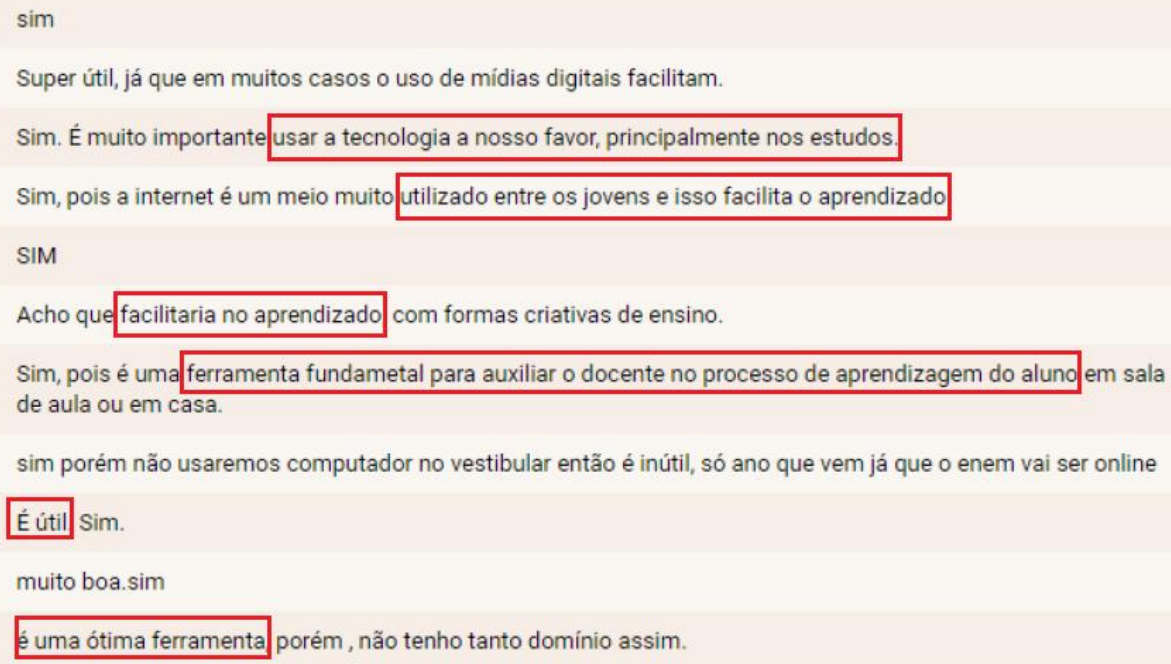

Fonte: dados da pesquisa.

As respostas apresentadas anteriormente dialogam com a perspectiva teórica apresentada na seção dois desse artigo, em particular com a ideia de Soffner (2013, p. 159) que preconiza "a construção de uma nova educação deverá tirar proveito, mas também garantir o acesso à informação e aos conteúdos, fazendo do educando um descobridor". Nesse sentido, as falas dos estudantes convergem ao que propõe Freire (2001, p.98), o qual argumenta que sobre a utilização de computadores "na 
educação, em lugar de reduzir, pode expandir a capacidade crítica e criativa de nossos meninos e meninas. Dependendo de quem o usa, a favor de que e de quem e para quê".

Sobre o segundo questionário, a pergunta relativa à contribuição do aplicativo no aprendizado sobre funções, foi recebida duas respostas afirmando ser mais fácil visualizar os seus gráficos no plano cartesiano. Outra resposta revelou um aprendizado da existência do processo de raciocínio quando o estudante afirmou que conseguiu compreender o processo de "raciocínio lógico-matemático".

A última pergunta mencionava o uso de mídias digitais em sala de aula e indagava se o estudante percebia potencialidades trazidas por elas nas relações de aprendizagem. Nas respostas, temos apontada uma relação entre a matemática e o "raciocínio lógico-matemático", bem como a visão de um discente inserido na cultura digital de que "podemos usar a tecnologia a nosso favor". Em outra resposta, fica destacado o potencial pedagógico dos diagramas interativos com controles deslizantes, que chamaram a atenção dos estudantes, conforme mostrado na imagem a seguir, que é um extrato das respostas apresentadas.

Figura 3: Captura de tela dos envios dos estudantes.

Já foi respondido, por isso recortei o seguinte parágrafo "Como a matemática é uma linguagem e ao aprender uma nova, temos que relacionar a algo que já sabemos, o método de visualizar e e compreender a partir disto ajuda criar o raciocínio lógico-matemático importante a mim e a população brasileira por meio de uma mídia digital."

Ótima! Principalmente pela dinâmica de poder mexer no gráfico digitalmente.

sim, mostra como podemos usar a tecnologia à nosso favor e para o futuro profissional e acadêmico também.

Fonte: dados da pesquisa.

Entendemos que o conjunto de respostas apresentadas nos questionários de alguma forma intenciona compreender que para os participantes da pesquisa, ao fazer uso das tecnologias digitais em um processo de ensino há uma "expressão natural do processo criado em que os seres humanos se engajam no momento em que forjam o seu primeiro instrumento com que melhor transformam o mundo" (FREIRE, 1975, p. 98 apud ALENCAR, 2009, p. 164).

\section{CONSIDERAÇÕES FINAIS}

Em função do desenvolvimento tecnológico sucederam-se mudanças no mercado de trabalho, o que tornou o uso de Tecnologias da Informação e da Comunicação (TIC) em sala de aula imperativo antes mesmo do distanciamento social. Com a pandemia de 2020 e as restrições de circulação e aglomeração ao redor do mundo, a educação como um todo precisou se reinventar, o que acabou acelerando esse processo. Entendemos nesse contexto que os AVA sejam ferramentas importantes, necessárias, porém não totalmente suficientes, para o trabalho de professores e professoras. Tais espaços virtuais deixaram de ser uma opção para tornarem-se praticamente a (única) alternativa para propostas de atividades, as quais ocorrem na modalidade à distância.

A plataforma e as atividades realizadas, na modalidade presencial, se mostraram pertinentes, uma vez que seu uso ocorreu na forma de um repositório na realização da sequência de atividades proposta pelo professor no laboratório de informática. O acesso por parte dos estudantes ocorreu de forma a não ter problemas e entendemos que o AVA permitiu uma postura ativa dos estudantes durante as aulas, além de ter oportunizado momentos de uma interação maior entre eles. $O$ envio 
de respostas funcionou para a produção de dados para a pesquisa, evidenciando a potencialidade referente à aplicação de avaliações que a utiliza.

No contexto do ensino estritamente a distância, a plataforma pode ser útil mesmo que ainda hajam limitações. A atividade citada foi realizada de maneira presencial, oportunizando assim que os problemas encontrados ao planejar fossem superados. Portanto, infere-se, a partir do experimento realizado, que a plataforma seja útil para atividades a distância, também para a realização de avaliações, já que permite a postagem de material com questões tanto dissertativas quanto de múltipla escolha e há um registro organizado das respostas as quais podem ser facilmente acessadas pelo professor. Ainda nesse sentido, um trabalho com Diagramas Interativos do GeoGebra possibilita uma visualização e manipulação dos objetos por parte dos estudantes durante a atividade.

Entendemos que a plataforma não deva ser utilizada sozinha, e sim com o uso combinado de outra rede social, tal como o Whatsapp, Facebook, Google sala de aula, entre outros, para contato instantâneo e explanação de dúvidas. Destaca-se também o poder de democratização do conhecimento que plataforma oferece, pois permite que as atividades postadas em grupos fiquem disponíveis de maneira pública para todos os usuários da plataforma gratuita do GeoGebra, o que entra em consonância com os dizeres consoantes da EP.

Uma última ressalva que se faz ao uso de AVA, e que se direciona na perspectiva da educação emancipatória, enquanto olhada na formação inicial docente, é a importância que estes tenham no processo de formação de professores com vistas a realizar esse tipo de trabalho docente à luz da ideia de Conte, Habowski e Rios (2018). Entendemos que se torna necessário às instituições oferecer preparação e qualificação para o uso de plataformas online e de ensino a distância, seja na formação inicial ou continuada de professores, os quais serão os vetores de novas possibilidades inerentes à aprendizagem dos estudantes.

\section{Agradecimentos}

Ao Instituto Federal de Educação, Ciência e Tecnologia do Rio Grande do Sul (IFRS) pelo acolhimento e parceria na execução da pesquisa realizada.

\section{REFERÊNCIAS}

ALENCAR, Anderson Fernandes. A tecnologia na obra de Álvaro Vieira Pinto e Paulo Freire.

Software Livre, Cultura Hacker e Ecossistema da Colaboração. Vicente Macedo de Aguiar (org), 2009, p. 151-187. São Paulo: Momento Editorial. 2009.

BICUDO, Maria Aparecida Viggiani. Pesquisa qualitativa e pesquisa qualitativa segundo a abordagem fenomenológica. Pesquisa qualitativa em educação matemática. Organização Marcelo de Carvalho Borba e Jussara de Loiola Araújo. $5^{a}$ ed. Belo Horizonte: Autêntica Editora, p. 111-124. 2013.

BRANDÃO, Carlos Rodrigues de Oliveira. O que é Educação Popular. São Paulo: Brasiliense. 2006.

BRASIL, Ministério da Educação. Orientações Educacionais Complementares aos Parâmetros Curriculares Nacionais. Bases Legais, Brasília, DF, MEC. 1999. 
BRASIL, Ministério da Educação. Orientações Educacionais Complementares aos Parâmetros Curriculares Nacionais (PCN+). Ciências da Natureza e Matemática e suas tecnologias. Brasília, DF, MEC. 2002.

BRASIL, Ministério da Educação.Orientações Curriculares para o Ensino Médio. Ciências da Natureza, matemática e suas tecnologias. Brasília, DF, MEC. 2006.

BRASIL. Ministério da educação. Base nacional comum curricular. Brasília, DF: MEC, 2018. Disponível em: http://basenacionalcomum.mec.gov.br/wpcontent/uploads/2018/06/BNCC_EnsinoMedio_embaixa_site_110518.pdf. Acesso em novembro de 2018.

DOTTA, Silvia. Uso de uma Mídia Social como Ambiente Virtual de Aprendizagem. Anais do XXII Simpósio Brasileiro de Informática na Educação - XVII WIE. Aracaju, Al, Brasil. 2011.

FANTIN, Mônica; GIRARDELLO, Gilka. Diante do abismo digital: mídia-educação e mediações culturais. Perspectiva, Florianópolis, v. 27, n. 1, 69-96, jan/jul. 2009.

FREIRE, Paulo. Ação cultural para a liberdade e outros escritos. Tradução de Claudia Schilling. Buenos Aires: Tierra Nueva. 1975.

FREIRE, Paulo. Pedagogia da Esperança: um reencontro com a pedagogia do oprimido.Rio de Janeiro: Paz e Terra. 1992.

FREIRE, Paulo. A Educação na Cidade. 5a ed. São Paulo: Cortez. 2001.

FREIRE, Paulo. Pedagogia da autonomia: saberes necessários para a prática educativa.44a ed. Rio de Janeiro: Paz \& Terra. 2013.

FREIRE, Paulo. Pedagogia do oprimido. 7a ed. Rio de Janeiro: Paz \& Terra. 2019.

MADRUGA, Zulma Elizabete de Freitas. Recursos tecnológicos como apoio no ensino presencial e a distância da disciplina de matemática. Anais do II Seminário Diálogos em Educação a Distância. Pelotas, RS, Brasil. 2017.

MASON, Robin. Using communications media in open and flexible learning.London: Kogan Page. 1994.

MASSENSINI, Rogério Luís. Inclusão digital: sob a ótima da cidadania plena. DataGramaZero, Revista da ciência e informação, v.12 n.2. 2011.

NAFTALIEV, Elena, YERUSHALMY, Michal. Interactive diagrams: alternative practices for the design of álgebra inquiry. Center for educational technology and university of Haifa, Israel. 2009.

PEREIRA, Dulcinéia de Fátima Ferreira, PEREIRA, Eduardo Tadeu. Revisitando a história da educação popular no Brasil: em busca de um outro mundo possível. Revista HISTEDBR on-line, Campinas, n.40, p.72-89, 2010.

PETRIA, Vânia Fuchter. 0 desafio da educação na cultura digital. Trabalho de Conclusão de Curso, Universidade Federal de Santa Catarina, Taió, SC, Brasil. 2016.

PINI, Francisca Rodrigues de Oliveira. Educação popular e seus diferentes espaços: Educação social de rua, prisional e do campo. IV congresso internacional de pedagogia, São Paulo, SP, Brasil. 2012. 
PINI, Francisca Rodrigues de Oliveira, e Adriano, Ana Lívia. Educação, participação política e direitos humanos. Educação em direitos humanos: abordagens teórico-metodológicas e éticopolíticas. São Paulo, Editora e livraria Paulo Freire, p. 15-29. 2011.

SILVA, Rodrigo Sychocki da; PINTO, Shéridan dos Reis. Funções quadráticas e tecnologias móveis: ações cooperativas em um experimento no Ensino Médio. Góndola, Enseñanza y aprendizaje de las Ciencias, 14(1), p. 108-125. 2019.

SWAN, Karen. Relationships Between Interactions and Learning in Online Environments. Kent State University: The Sloan Consortium. 2004.

Submissão: 17/12/2020

Aceito: 12/01/2021 